\title{
Epidemiological and therapeutic studies of camel mange in Fafan zone, Eastern Ethiopia
}

\author{
Teka Feyera ${ }^{1}$, Petros Admasu ${ }^{2 *}$, Ziad Abdilahi $^{3}$ and Bahar Mummed ${ }^{4}$
}

\begin{abstract}
Background: Camel mange is an economically important parasitic disease affecting productivity in camel rearing areas of the world if appropriate treatment is not instituted.

Methods: A cross-sectional and a controlled field trial were carried out to study the epidemiology of camel mange in Fafan zone, Eastern Ethiopia, and evaluate the efficacy of ivermectin and diazinon in the control of mange infestation in camels on the basis of clinical and parasitological evidence, respectively. Three groups of naturally infested camels and one group of healthy camels each composed of 6 individuals were enrolled: the two infested groups received either ivermectin or diazinon, and the other groups remained untreated.

Results: The overall prevalence rate of mange in camels in the study area was $31.5 \%$ and the only identified species was Sarcoptes scabiei. The prevalence rate was found to significantly vary $(p<0.05)$ in relation to body condition and herd size of camels. Both drugs showed significant variation $(p<0.05)$ on improving clinical and body condition scores. Clearance of mange lesions occurred with both drugs; however, re-infestation was observed in diazinon treated group. Ivermectin significantly improved $(p<0.05)$ both body condition and clinical scores whereas diazinon markedly improved only the later.

Conclusion: In conclusion, camels in the study area harbored considerable level of S. scabiei which warrants institution of an integrated control approach by administration of ivermectin while also sanitating the animal environment.
\end{abstract}

Keywords: Camel, Epidemiological, Fafan zone, Therapeutic, Ivermectin, Diazinon, Sarcoptes scabiei

\section{Background}

Camel (Camelus dromedarius) is an important livestock species in the pastoral economy [1], and is commonly distributed in subtropical dry areas in Africa and Asia [2]. Ethiopia is one of the largest camel populated countries in the world. With 1,102,119 numbers of camels, Ethiopia ranks third in Africa next to Somalia and Sudan [3]. In arid and semi-arid areas which are not suitable for crop and animal production, camels are superior to all other livestock in terms of food security serving as the main source of milk, meat and draft power $[4,5]$. Camel is also a financial reserve and plays an important

\footnotetext{
*Correspondence: petrosadmasut@gmail.com

${ }^{2}$ Department of Biomedical Sciences, Jigjiga University, College of Veterinary Medicine, P. O. Box 1020, Jigjiga, Ethiopia

Full list of author information is available at the end of the article
}

role in social prestige and wealth. However, despite its significant contribution to the livelihood of the pastoralist society, the camel is one of the neglected domestic livestock by the scientific community [6].

Slow reproduction cycle, high calf mortality and health problems are major constraints in increasing camel herd population and productivity. Ectoparasites (mites, ticks and insects) of the camel and their capacity to disease transmission are important constraints to productivity and performance [7]. Camel mange, an extremely contagious ectoparasitism caused by the parasitic mite Sarcoptes scabiei and transmitted by direct or indirect contact, is one of the most important parasitic diseases affecting camel [8].

Significant economic loss of camel productivity to mange has been recorded $[9,10]$. Despite these facts, there is very 
little systematic research on mange and other ectoparasites of camels in Ethiopia. Few researchers have made attempts of reporting common ectoparasites affecting camel in different districts of Eastern Ethiopia [1, 2]. However, information on ectoparasitic infestation of camels, especially mange, in Fafan zone is inadequate despite the comparatively large number of these animals in the area, and little attention has been devoted so far to control of mange in local camels. The present work was, therefore, carried out to improve knowledge of the epidemiology of mange in camels and to evaluate the efficacy of ivermectin and diazinon for control of camel mange under field conditions.

\section{Methods}

\section{Description of the study area}

The study was carried out in selected districts of Fafan zone, Somali Regional state of Ethiopia. The zone is situated at $620 \mathrm{~km}$ southeast of Addis Ababa, the capital of the country. It has eight districts, namely Jigjiga, Kebribeyah, Harshin, Babile, Awbare, Gursum, Tullu Guled and Gololchen. Temperature of the area is generally high all the year round with mean minimum and maximum values being around 20 and $35{ }^{\circ} \mathrm{C}$, respectively. The mean annual rainfall is $660 \mathrm{~mm}$ and bimodal. The camel population of the zone is 81,221 [11]. The livelihood of the community is based mainly on pastoralism (34.1\%), agro-pastoralism (56.8 \%) and sedentary production systems (9.1\%) [12].

\section{Study design and period}

The study was carried out from November 2014 to April 2015. A cross-sectional study design was employed for the epidemiological study and an experimental study design (controlled field trial) was used for the therapeutic study on selected camel herds.

\section{Epidemiological study}

\section{Study population and sample size determination}

Babile, Kebribeyah and Gursum districts were selected based on high camel population, accessibility and convenience. Six kebelles/peasant associations (PAs), two from each district, were identified. Then, camel herds were selected using simple random sampling method [13], whereas subjects within herd were selected using systematic random sampling method [14]. Animals above 1 year old were included in this study irrespective of their sex, body condition score and husbandry condition. Camel herds were visited and sampled early in the morning before being released to field, and samples were then taken to Jigjiga University Veterinary Laboratory Centre.

The sample size was determined based on the formula recommended by Thrusfield [15] as follows:

$$
\mathrm{N}=\frac{(1.96)^{2} * \operatorname{Pexp} * \mathrm{q}}{\mathrm{d}^{2}}
$$

Where,

$\mathrm{N}$ sample size required

Pexp expected prevalence

q 1-Pexp

$\mathrm{d}$ desired absolute precision

Sample size determination was based on $25.9 \%$ expected prevalence according to Abebe [2] with $5 \%$ precision and $95 \%$ level of significance. Accordingly, the sample size required for this study was 295 . The proportional probability to size approach [16] was used to determine the number of camels to be included from each district. Analyzed risk factors included: sex, age, body condition score, origin and herd size.

\section{Examination for mange mites}

Skin scrapings from clinically suspected cases of mange were collected and preserved in $10 \%$ formalin. $10 \%$ potassium hydroxide $(\mathrm{KOH})$ was then added to the sediment to digest or clean the scraped material of skin, hair and other debris, so that mites were released from scabs. Finally, the specimens were carefully placed on slides for microscopic examination (40x or $100 \times$ magnification). Identification of the mange mite species was based on the morphological characteristics described by Urquhart et al. [17].

\section{Age determination}

Age was determined by dental eruption according to Khan et al. [18]. Camels were divided into two age categories ( $>3$ year and $\leq 3$ year) based on their puberty profile [19].

\section{Body condition scoring}

The body conditions of sampled camels were categorized as good, medium and poor according to Faye et al. [20]. Assessment was made on days 0, 7, 14, 21, 28, 42 and 56 for all groups.

\section{Therapeutic study}

This controlled field trial was carried out on camels naturally infested with mange mites. After conducting the epidemiological survey, four camel herds were selected for the therapeutic study based on their appropriateness for the experiment. This was based on communities' complaints on intensity of the disease, personal observations during the field work, accessibility, number of affected camels in the specific village, and owners' compliance. Overall, three groups of naturally infested camels and one group of healthy (uninfested) camels each composed of 6 animals were enrolled. Grouping was by random selection of the animals. During the therapeutic trial, camels in all 
Table 1 Prevalence of mange infestation in camels of the study area, on the basis of different risk factors

\begin{tabular}{|c|c|c|c|c|c|}
\hline Variable & Category level & Number examined & Number positive (\%) & $x^{2}$ & $p$-value \\
\hline & El-bahay & 45 & 17 (38 \%) & & \\
\hline & Kollej & 50 & $12(24 \%)$ & & \\
\hline \multirow[t]{4}{*}{ Place of origin } & Arro-aska & 47 & $17(36.17 \%)$ & 4.29 & 0.58 \\
\hline & Gol-marodi & 46 & $11(24.1 \%)$ & & \\
\hline & Guyow & 50 & $18(32.70 \%)$ & & \\
\hline & Garbo-hare & 57 & 18 (36 \%) & & \\
\hline \multirow[t]{2}{*}{ Sex } & Male & 84 & 27 (32.1\%) & 0.021 & 0.885 \\
\hline & Female & 211 & 66 (31.1\%) & & \\
\hline \multirow[t]{3}{*}{ Age } & $>3$ year & 223 & $72(32.2)$ & 0.245 & 0.620 \\
\hline & $\leq 3$ year & 72 & $21(29.16)$ & & \\
\hline & Good & 110 & $18(16.3)$ & & \\
\hline \multirow[t]{3}{*}{ Body condition } & Medium & 148 & $53(35.8)$ & 26.34 & $<0.001$ \\
\hline & Poor & 37 & $22(59.5)$ & & \\
\hline & $<20$ & 107 & $24(22.4)$ & 16.22 & $<0.001$ \\
\hline \multirow[t]{2}{*}{ Herd size } & $20-40$ & 136 & $41(30.1)$ & & \\
\hline & $>40$ & 52 & $28(53.8)$ & & \\
\hline
\end{tabular}

groups were kept under traditional management system with similar husbandry facilities extended to them. They were allowed for free grazing in feed abundant areas usually mixed with other livestock.

\section{Clinical examination and scoring of skin lesions}

All camels were subjected to whole body examination for clinical signs of mange (erythema, pruritus, alopecia, hyperpigmentation and crusting) and clinically scored according to a system previously applied to horses with chorioptic mange [21]. Briefly, blinded clinical dermatological assessments (severity of the lesions and degree of recovery if any) were taken on days $0,7,14,21,28,42$ and 56 for all groups and scores were recorded as follows: 0: no clinical signs; 1 : mild signs and high degree of recovery; 2: moderate signs and degree of recovery; and 3: severe signs and low degree of recovery.

\section{Parasitological examination}

Prior to enrollment in the study, the camels were tested for presence of mites (larvae, nymphs and adults) in skin scrapings obtained from at least 3-4 sites. Scrapings (see above) were performed on days $0,7,14,21,28,42$ and 56 of treatment at those sites where suspected lesions were present, and in selected healthy sites (the head, base of the neck, mammary gland, prepuce and flank) most likely to yield mites.

\section{Therapy protocols}

The camels with typical lesions of mange, harboring mites, were divided and randomly assigned by coin toss into 3 groups, and for comparisons, a fourth group of healthy camels were also included. Two miticidal agents, ivermectin (Ivomec, Change Qiankuma Veterinary Pharmaceutical, Co. Ltd., China) and diazinon (Diazinol, E.C, Company Kat Relzayat, Pesticides and Chemical, Co. Ltd., Egypt) were chosen for this field trial based on their commercial availability, patronage by camel herders and veterinary clinics in the study area, and recommendation from literature. Camels in group I received diazinon 10 days apart at a concentration of $0.1 \%$ (spray), whereas camels under group II received two doses of ivermectin 10 days apart at dose rate of $0.2 \mathrm{mg} \mathrm{kg}^{-1}$ of body weight (subcutaneous injection). Group III (infested) and group IV (healthy) were left as positive and negative control with no treatment applied. The efficacy of each regimen was evaluated on the basis of clinical and parasitological evidence on day zero (day of treatment) and on days $7,14,21,28,42$ and 56 posttreatment.

\section{Ethical approval}

Ethical approval was obtained from Directorate of Research, Publication and Technology Transfer Research Ethics Committee, Jigjiga University, Ethiopia.

\section{Statistical analysis}

For both the epidemiological and therapeutic studies, data was organized, edited and analyzed using statistical package for social sciences (SPSS), Version 20. The prevalence of mange was assessed using descriptive statistics. To assess differences in the prevalence and frequency of mange and association of potential risk factors (sex, age, body condition, herd size and origin) with the prevalence, the Chi-square $\left(X^{2}\right)$ test was used. 
Table 2 Effect of ivermectin and diazinon treatment on mange infestation in camels

\begin{tabular}{|c|c|c|c|c|c|c|c|c|c|c|c|c|c|c|}
\hline \multirow[t]{2}{*}{ Group } & \multicolumn{2}{|l|}{ D0 } & \multicolumn{2}{|l|}{ D7 } & \multicolumn{2}{|l|}{ D14 } & \multicolumn{2}{|l|}{ D21 } & \multicolumn{2}{|l|}{$\mathrm{D} 28$} & \multicolumn{2}{|l|}{ D42 } & \multicolumn{2}{|l|}{ D56 } \\
\hline & NPA & ENM & NPA & ENM & NPA & ENM & NPA & ENM & NPA & ENM & NPA & ENM & NPA & ENM \\
\hline Ivermectin & 6 & ++ & 0 & - & 0 & - & 0 & - & 0 & - & 0 & - & 0 & - \\
\hline Diazinon & 6 & ++ & 0 & - & 0 & - & 0 & - & 0 & - & 0 & - & 1 & + \\
\hline Infested untreated & 6 & ++ & 6 & + & 6 & ++ & 6 & + & 0 & + & 6 & ++ & 6 & ++ \\
\hline Healthy untreated & 0 & - & 0 & - & 0 & - & 0 & - & 0 & - & 0 & - & 1 & + \\
\hline
\end{tabular}

+: 1-10 mites; ++: 10-100 mites; -: No mites; $n$ (number of animals in each group) =6; $D=$ day; $D 0=$ the day treatment commenced; NPA = Number of Positive animals; ENM = Estimated number of mites

For the therapeutic study, results and data generated from the trial were expressed as mean \pm standard error. One way analysis of variance (ANOVA) and the student $t$-test was employed for inter-group and intra-group difference analysis. Results were deemed statistically significant if $p \leq 0.05$ at $95 \%$ confidence intervals.

\section{Results}

\section{Epidemiological study}

The present study revealed that camels of the study area are remarkably exposed to mange caused by sarcoptic mites. An overall prevalence of $31.5 \%$ was recorded (Table 1). S. scabiei was identified as the only mite species in all skin scrapings collected from the suspected lesions of examined camels. Analysis results revealed no statistically significant difference related to origin, sex and age categories of the studied camels. As opposite, herd size and poor body condition score were significantly $(P<0.001)$ and positively associated to mange prevalence.

\section{Therapeutic study}

Treatment with ivermectin and diazinon was similarly effective on sarcoptic mange infestation, and beneficial on clinical and body condition scores. Both treatments resulted in the clearance of skin of mangy camels (Table 2). No parasitic stages were found throughout the observation period post application of ivermectin. However, reinfestation was observed in a camel during the 8th week post diazinon application. Furthermore, one of the healthy untreated animals was found infested with mange at the end of the observation period.
Throughout the observation period, treatment with either drug did not result in significant improvement in the body condition score compared to pre-treatment values and amongst themselves (Table 3). Relative to positive controls, treatment with ivermectin seemed to improve the body condition score ( 28 through 56 days post-treatment; $p<0.05)$, whereas the diazinon group had a similar body condition score except in week 7 . The positive and negative controls showed deteriorating and stable body condition scores, respectively.

Treatment with either drug resulted in a considerable improvement in the clinical score compared with pretreatment values and the positive controls (Table 4). Differences were statistically significant from the third week post treatment to the end of the trial. All treated camels showed high degree of recovery with reference to skin texture, healing of skin lesions and disappearance of crusts. However, the infested untreated camels showed worsening skin appearance compared to the treated groups.

\section{Discussion}

The present study demonstrated an overall prevalence of $31.5 \%$ mange mite infestation in the studied camel herds. This value is higher than the figure in Awol et al. [22], Dinka et al. [1], Lawal et al. [23] and Chaudhry et al. [24] who reported 16.7, 10.7, 3.5 and $3.14 \%$ prevalence from Northern Ethiopia, Eastern Ethiopia, SokotoNigeria and Cholistan-Pakistan, respectively and lower than a prevalence of $83 \%$ reported by $\mathrm{Al}$-ani et al. [25] in Jordan. Variation in genetics, environment, accessibility to veterinary services, herd size and other husbandry practices could justify these differences.

Table 3 Effect of ivermectin and diazinon treatment on body condition score change of experimental camels

\begin{tabular}{llllllll}
\hline Goup & D0 & D7 & D14 & D21 & D28 & D42 & D56 \\
\hline Ivermectin & $1.83 \pm 0.17$ & $1.67 \pm 0.21$ & $1.67 \pm 0.21$ & $2.17 \pm 0.17$ & $2.33 \pm 0.21^{\mathrm{a}}$ & $2.50 \pm 0.22^{\mathrm{a}}$ & $2.50 \pm 0.22^{\mathrm{a}}$ \\
Diazinon & $2.00 \pm 0.26$ & $2.00 \pm 0.26$ & $2.17 \pm 0.17$ & $2.00 \pm 0.26$ & $2.67 \pm 0.21$ & $2.33 \pm 0.21^{\mathrm{a}}$ & $2.00 \pm 0.26$ \\
Infested untreated & $2.00 \pm 0.00$ & $1.83 \pm 0.17$ & $1.83 \pm 0.17$ & $1.50 \pm 0.22$ & $1.50 \pm 0.22$ & $1.33 \pm 0.21$ & $1.50 \pm 0.22$ \\
Healthy untreated & $2.33 \pm 0.21$ & $2.67 \pm 0.17$ & $2.67 \pm 0.17$ & $2.67 \pm 0.17$ & $2.33 \pm 0.21^{\mathrm{a}}$ & $2.67 \pm 0.17^{\mathrm{a}}$ & $2.67 \pm 0.17$ \\
\hline
\end{tabular}

Values are mean $\pm \mathrm{SEM} ; \mathrm{n}$ (number of animals in each group) $=6 ; \mathrm{D}=$ day; $\mathrm{D} 0=$ the day treatment commenced; $\mathrm{SEM}=$ standard error of mean; all superscripts indicate significance at $p<0.05$ ( ${ }^{\mathrm{a}}$ compared to infested untreated) 
Table 4 Effect of ivermectin and diazinon treatment on clinical score change of experimental camels

\begin{tabular}{llllllll}
\hline Group & $\mathrm{D} 0$ & $\mathrm{D} 7$ & $\mathrm{D} 14$ & $\mathrm{D} 21$ & $\mathrm{D} 28$ & D42 & D56 \\
\hline Ivermectin & $1.83 \pm 0.75^{\mathrm{b}}$ & $1.67 \pm 0.52^{\mathrm{b}}$ & $1.33 \pm 0.52^{\mathrm{b}}$ & $1.00 \pm 0.63^{\mathrm{ab}}$ & $0.67 \pm 0.52^{\mathrm{a}}$ & $0.67 \pm 0.82^{\mathrm{a}}$ & $0.67 \pm 0.52^{\mathrm{a}}$ \\
Diazinon & $1.67 \pm 0.82^{\mathrm{b}}$ & $2.00 \pm 0.90^{\mathrm{b}}$ & $1.33 \pm 0.52^{\mathrm{b}}$ & $0.83 \pm 0.41^{\mathrm{ab}}$ & $0.33 \pm 0.52^{\mathrm{a}}$ & $0.67 \pm 0.82^{\mathrm{a}}$ & $0.50 \pm 0.84^{\mathrm{a}}$ \\
Infested untreated & $1.67 \pm 0.82$ & $1.13 \pm 0.52$ & $1.67 \pm 0.82$ & $2.17 \pm 0.41$ & $2.00 \pm 0.63$ & $2.17 \pm 0.75$ & $2.33 \pm 0.53$ \\
Healthy untreated & $0.00 \pm 0.00^{\mathrm{a}}$ & $0.00 \pm 0.00^{\mathrm{a}}$ & $0.00 \pm 0.00^{\mathrm{a}}$ & $0.00 \pm 0.00^{\mathrm{a}}$ & $0.00 \pm 0.00^{\mathrm{a}}$ & $0.00 \pm 0.00^{\mathrm{a}}$ & $0.33 \pm 0.52^{\mathrm{a}}$ \\
\hline
\end{tabular}

Values are mean $\pm \mathrm{SEM} ; \mathrm{n}$ (number of animals in each group) $=6 ; \mathrm{D}=$ day; $\mathrm{D} 0=$ the day treatment commenced; $\mathrm{SEM}=$ standard error of mean; all superscripts indicate significance at $p<0.05$ ( ${ }^{\mathrm{a}}$ compared to infested untreated; ${ }^{\mathrm{b}}$ compared to healthy untreated)

S. scabiei was identified as the only mite species in all scrapings collected from suspected skin lesions. This observation is in general agreement with reports by various authors [1, 22, 23]. Even though both sarcoptic and chorioptic mange mites have been reported, sarcoptic mange caused by $S$. scabiei is by far the most common, contagious and serious condition in camels [26, 27]. Similarly as Megersa et al. [28] and Dinka et al. [1] from southeastern and eastern Ethiopia, respectively, the prevalence of mange did not differ according to the origin, sex, and age of the camels. Not surprisingly, mite prevalence was highest in camels with poor body condition score $(59.4 \%)$. Moreover, the prevalence of $S$. scabiei increased significantly in herds with a larger size. Probably, camels living in larger herds are more prone to come into contact with infested animals, e.g., during herding, housing and suckling.

Amongst factors that may influence the condition of camels, control of ectoparasites with effective chemicals such as endectocides and ectoparasiticides is very important. These drugs can be used for the benefit of local epidemiological awareness [29]. In the present work, their efficacy was evaluated on the basis of clinical improvement and the parasitological findings. Data revealed that the clearance of skin of infested camels occurred following either treatments (with ivermectin and diazinon). Successful use of ivermectin in mangy camels at a dose rate of $200 \mu \mathrm{g} / \mathrm{kg}$ body weight has been reported [30]. In the present study, mangy animals treated with ivermectin felt rapidly more comfortable and docile due to quicker relief from itching.

While no lesions were found during microscopic examination of the skin scrapings up to the $7^{\text {th }}$ week post treatment with diazinon, re-infestation was observed at the $8^{\text {th }}$ week with resurgence of the typical mangy skin lesions. As opposite, the animals treated with ivermectin neither showed any lesions nor signs of re-infestation throughout the observation period after treatment. The result of the present work also agrees with the reports of Bala and Rath [31] and Abdally [29], who stated that ivermectin have good efficacy against sarcoptic mites. Sprays such as diazinon have also been used to clean the animal environment to eliminate the risk of recurrent infestation from fomites [32, 33]. Saber and Ahmed [34] suggested that using acaricides for treatment in addition to spraying animal environment (bedding, wall and fomites) is the best protocol for controlling mange in water buffaloes.

In this field trial, the treated camels were not isolated from the herd, hence they had opportunity of contact with other sick animals and a contaminated environment. It was, thus, impossible to tell how and when they became re-infested. However, the results of this study demonstrated that re-infestation may occur if treated animals are not isolated from untreated similars or infected premises and environment [35].

\section{Conclusion}

The present study conducted in Fafan zone, eastern Ethiopia showed that camels living in this area are frequently infested with mange mites with a likely impact on their health and productivity. The overall prevalence of mite infestation was $31.5 \%$, S. scabiei being the only mite found in affected camels. Origin, sex and age were not significantly associated with the prevalence of mange mite infestation, while a positive association existed with poor body condition and herd size. The therapeutic field trial showed obvious clinical improvement in all the treated camels. The study also revealed that ivermectin was relatively more efficacious than diazinon, as measured by analyses of skin scrapings, and body condition and clinical score changes.

\section{Competing interests}

The authors declare that they have no competing interests.

\section{Authors' contributions}

TF and PA conceived and designed the study, conducted data analysis, and wrote the first draft; TF: coordinated the data collection; ZA and BM provided parasitological expertise and efficacy trial. All authors read and approved the final version of the manuscript.

\section{Authors' information}

TF: DVM and M.Sc. in Pharmacology, Assistant Professor in Department of Parasitology and Pathology, College of Veterinary Medicine, Jigjiga University, P.O.Box 1020, Jigjiga, Ethiopia. PA: DVM and M.Sc. in Biomedical Sciences, Assistant Professor in Department of Biomedical Sciences, College of Veterinary Medicine, Jigjiga University, P.O.Box 1020, Jigjiga, Ethiopia. ZA: Regional Animal Health Investigation and Diagnostic Centre, Jigjiga, Ethiopia. BM: BVSc. degree in Veterinary Laboratory Technology, Assistant Lecturer in Department of Microbiology and Public Health, College of Veterinary Medicine, Jigjiga University, P.O.Box 1020, Jigjiga, Ethiopia. 


\section{Acknowledgements}

The authors would like to thank Jigjiga University Directorate of Research, Publication and Technology Transfer for funding this research.

\section{Author details}

'Department of Parasitology and Pathology, Jigjiga University, College of Veterinary Medicine, P. O. Box 1020, Jigjiga, Ethiopia. ${ }^{2}$ Department of Biomedical Sciences, Jigjiga University, College of Veterinary Medicine, P. O. Box 1020, Jigjiga, Ethiopia. ${ }^{3}$ Regional Animal Health Investigation and Diagnostic Centre, Jigjiga, Ethiopia. ${ }^{4}$ Department of Microbiology and Public Health, Jigjiga University, College of Veterinary Medicine, P. O. Box 1020, Jigjiga, Ethiopia.

Received: 6 October 2015 Accepted: 23 November 2015

Published online: 01 December 2015

\section{References}

1. Dinka A, Eyerusalem B, Yacob HT. A study on major ectoparasites of camel in and around Dire-Dawa, Eastern Ethiopia. Rev Med Vet. 2010;161(11): 498-501.

2. Abebe F. Prevalence and intensity of ectoparasites infestation in ISSA camels, Eastern Ethiopia, DVM thesis. Debre-Zeit: Faculty of Veterinary Medicine, Addis Ababa University; 2001.

3. Central Statistical Authority. Agricultural sample enumeration statistical abstract. Addis Ababa, Ethiopia: Federal Democratic Republic of Ethiopia; 2013.

4. Bekele T. Milk production, fluid balance and temperature regulation in lactating camels (Camelus dromedarius), DVM Thesis. Uppsala: Swedish University of Agriculture; 2010.

5. Schwartz HJ. The camel (Camelus dromedarius) in Eastern Africa. In: Schwartz HJ, Dioli M, editors. The one-humped camel (Camelus dromedarius) in eastern Africa: a pictorial guide to diseases, health care, and management. Weikersheim: Verlag Josef Margraf; 1992. p. 1-7.

6. Yesihak Y, Bekele T. Growth pattern of one humped camel (Camelus dromedarius). Ethiopia: Proceeding of the 11th Annual Conference of the Ethiopian Society of Animal Production (ESAP) held in Addis Ababa; 2003.

7. Dioli M, Stimmelmayr R. Important camel diseases, health care and management. Berlin: Schonwald Druck; 1992.

8. Kumar D, Raisinghani PM, Manohar GS. Sarcoptic mange in camels: a review. In: Proceeding of the 1st international camel conference. London: Newmarket Press; 1992.

9. Higgins AJ. Common ectoparasites of the camel and their control. Br Vet J. 1985;141:197-216.

10. Basu AK, Aliyu AL, Mohammed A. Prevalence of sarcoptic mange in camels (Camelus dromedarius) in Nigeria. J Camel Prac Res. 1995;2:141.

11. Central Statistical Agency. Agricultural sample survey 2007/08.Volume I report on livestock, and livestock characteristics for private peasant holdings. Addis Ababa: Federal Democratic Republic of Ethiopia; 2008.

12. Belaynesh D. Floristic composition and diversity of the vegetation, soil seed bank flora and condition of the rangelands of the Jigjiga Zone, Somali Regional State, Ethiopia, MSc Thesis. Ethiopia: School of Graduate Studies, Haramaya University; 1995

13. Levy PS, Lemeshow S. Sampling of populations: methods and applications. New York: Wiley and Sons; 2008.

14. Elsayir HA. Comparison of precision of systematic sampling with some other probability samplings. Am J Theor App Stat. 2014;3(4):111-6.

15. Thrusfield M. Veterinary epidemiology. 3rd ed. London: Blackwell Science; 2005.

16. Chromy JR. Probability Proportional to Size (PPS) sampling. Enc Surv Res Meth. 2008; doi:10.4135/9781412963947.

17. Urquhart GM, Armour A, Duncan JL, Jennings FW. Veterinary parasitology. 2nd ed. London: Blackwell Science; 1996.

18. Khan B, labal A, Riaz M. Production and management of camels. Faisalabad: University of Agriculture; 2003.

19. Mukasa-Mugerwa E. The camel (Camelus dromedarius). A bibliographical review. Addis Ababa: International Livestock Center for Africa; 1981.

20. Faye B, Bengoumi M, Viateau E, Chilliard Y. Adipocyte patterns of adipose tissue in camel hump and kidney. J Camel Prac Res. 2001:8:29-33.

21. Rendle DI, Cottle HJ, Love S, Hughes KJ. Comparative study of doramectin and fipronil in the treatment of equine chorioptic mange. Vet Rec. 2007;161: 335-8.
22. Awol N, Kiros S, Tsegaye Y, Ali M, Hadush B. Study on mange mite of camel in Raya-Azebo district, northern Ethiopia. Vet Res Forum. 2014;5(1):61-4.

23. Lawal MD, Ameh IG, Ahmed A. Some ectoparasite of Camelus dromedarius in Sokoto. Nig J Entomol. 2007:4:143-8.

24. Chaudhry HR, Ashraf S, Chaudhry M, Iqbal Z, Ali M, Jamil T, et al. Prevalence of common diseases in camels of Cholistan desert, Pakistan. J Inf Mol Biol. 2014;2(4):49-52.

25. Al-Ani FK, Sharrif LA, Al-rawashdeh OF, Al-Qudah KM. Camel diseases in Jordan. In: Proceeding of the third annual meeting for animal production under arid condition. UAE: United Arab Emirates University; 1998.

26. Pegram RG, Higgins AJ. Camel ectoparasites: a review. In: Proceedings of the first international camel conference. London: Newmarket Press; 1992.

27. Parsani HR, Veer S, Momin RR. Common parasitic diseases of camel. Vet World. 2008;1(10):317-8.

28. Megersa B, Damena A, Bekele J, Adane B, Sheferaw D. Ticks and mange mites infesting camels of Boran pastoral areas and the associated risk factors, southern Ethiopia. J Vet Med Anim Health. 2012;4(5):71-7.

29. Abdally $\mathrm{MH}$. Acaricidal efficacy of Ivomec (ivermectin) and Dectomax (doramectin) on sarcoptic mange mites (Sarcoptes spp.) of Arabian camels (Camelus dromedarius) in Saudi Arabia. J Entomol. 2010;7(2):95-100.

30. Veer S, Momin RR, Parsani HR. Therapeutic efficacy of doramectin against sarcoptic mange in camel. J Vet Parasitol. 2001;15:75-6.

31. Bala A, Rath SS. Comparative efficacy of doramectin, ivermectin and amitraz against sarcoptic mange in buffalo calves. Indian Vet J. 2006;83:75-6.

32. Arends JJ, Skogerboen TI, Ritzhaupt IK. Persistent efficacy of doramectin and ivermectin against experimental infestations Sarcoptes scabiei in swine. Vet Parasitol. 1999;82:71-9.

33. Cadiergues MC, Laguerre C, Roques M, Franc M. Evaluation bioequivalence of two formulations of deltamethrin for treatment of sheep with psoroptic mange. Am Vet J. 2004;65:151-4.

34. Saber K, Ahmed AR. Epidemiological studies of Egyptian buffaloes mange with special reference to efficacy of different therapeutic for treatment of mange. Assiut: Dept. of Animal Hygiene and Dept. of Animal Medicine (Infectious diseases), Faculty of Veterinary Medicine, Assiut University; 2001.

35. Radostits OM, Gay CC, Blood DC, Hinchcliff KWK, Gay C. Veterinary medicine: a textbook of the diseases of cattle, sheep, pigs, goats and horses. 9th ed. London: WB Saunders; 2000.

\section{Submit your next manuscript to BioMed Central and we will help you at every step:}

- We accept pre-submission inquiries

- Our selector tool helps you to find the most relevant journal

- We provide round the clock customer support

- Convenient online submission

- Thorough peer review

- Inclusion in PubMed and all major indexing services

- Maximum visibility for your research

Submit your manuscript at www.biomedcentral.com/submit 